\title{
A Função Adverbial de "Inteligência": Definições e Usos em Psicologia
}

\author{
Jorge M. Oliveira-Castro ${ }^{1}$ e Karina M. Oliveira-Castro \\ Universidade de Brasília
}

\begin{abstract}
RESUMO - Não há consenso em psicologia sobre a natureza, definição e nível de análise nas investigações relacionadas ao conceito de inteligência. A análise do uso deste conceito na linguagem cotidiana indicou que o mesmo exerce função adverbial, a qual caracteriza uma ação como bem-sucedida. O conceito é usado em níveis diferentes, funcionando como um resumo adverbial das ações de um indivíduo de forma geral ou de suas habilidades específicas. Como "sucesso" é relativo a valores culturais, a definição de inteligência também depende da cultura. A função adverbial pode vir a explicar pelo menos parte das divergências e controvérsias encontradas em psicologia.
\end{abstract}

Palavras-chave: inteligência; raciocínio; análise conceitual; linguagem cotidiana.

\section{The Adverbial Function of "Intelligence": Definitions and Uses in Psychology}

\begin{abstract}
There is no consensus concerning the nature, definition and level of analysis in investigations related to the concept of intelligence. The analysis of the use of this concept in ordinary language indicated that it has an adverbial function, which characterizes an action as successful. The concept is used at different levels, functioning as an adverbial summary of an individual's actions in general or his specific abilities. As "success" is relative to cultural values, the definition of intelligence also depends upon the culture. The adverbial function may explain at least in part the disagreements and controversies found in psychology.
\end{abstract}

Key words: intelligence; reasoning; conceptual analysis; ordinary language.

Investigações teóricas e empíricas relacionadas ao conceito de inteligência têm ocupado uma posição de destaque na história da psicologia desde a época de sua fundação no final do Século XIX (cf. Galton, 1869, 1883). Esta longa história está, no entanto, repleta de discordâncias sobre a maneira de descrever, medir e investigar os fenômenos de interesse, além de envolver sérias controvérsias sobre a utilização dos resultados provenientes dos testes que supostamente medem o nível de inteligência dos indivíduos. De acordo com vários autores, muitas destas discordâncias provêm da falta de consenso sobre a definição e conceituação de inteligência (e.g., Almeida, 1994, 1996; Howard, 1993; Sternberg, 1997; Sternberg \& Kaufman, 1998).

Partindo da idéia de que uma análise da lógica do uso dos conceitos psicológicos na linguagem cotidiana pode ser útil para esclarecer questões teóricas em psicologia (cf. Harzem \& Miles, 1978; Oliveira-Castro, 1992, 1993, 2000; Oliveira-Castro \& Harzem, 1990; Peters, 1958; Ryle, 1949), uma análise conceitual de inteligência foi realizada no presente trabalho. Esta análise consistiu em caracterizar a lógica do uso do conceito na linguagem cotidiana e compará-lo com alguns de seus típicos usos em psicologia. O resultado de tal análise indicou que o conceito tem função adverbial na linguagem cotidiana, não indicando ações específicas, mas formas de realizar quase qualquer ação. Esta característica

1 Endereço: Instituto de Psicologia, Universidade de Brasília, 70910900, Brasília, DF. E-mail: jocastro@unb.br adverbial do conceito pode em parte explicar a diversidade de definições e abordagens incongruentes encontradas na literatura psicológica.

\section{Usos de "Inteligência" em Psicologia}

O conceito de inteligência tem sido usado de forma muito diversa em psicologia. Quanto à natureza do fenômeno, diferentes autores têm relacionado o conceito a características biológicas dos indivíduos, a processos cognitivos, ou, ainda, a construtos teóricos, tais como traço latente. As características biológicas que tem sido relacionadas ao conceito têm variado desde aspectos do funcionamento do sistema nervoso, tais como velocidade de condução nervosa (Reed \& Jensen, 1992) ou taxa metabólica de glicose cortical (Haier, Nuechterlein, Hazlett, Wu \& Paek, 1988), a características estruturais do sistema nervoso, tal como o tamanho do cérebro (Willerman, Schultz, Rutledge \& Bigler, 1991).

Outros autores têm abordado os fenômenos relacionados ao conceito de inteligência decompondo o desempenho de tarefas complexas em componentes cognitivos. Neste caso, não se encontra na literatura consenso sobre o nível de análise mais adequado, podendo este ser baseado em componentes elementares de processamento de informação (e.g., Newell \& Simon, 1972), componentes cognitivos menos elementares em um nível de análise um pouco mais amplo (e.g., Sternberg, 1977), ou em estruturas cognitivas maiores (e.g., Piaget, 1952). 


\section{J. M. Oliveira-Castro e K. M. Oliveira-Castro}

Os fenômenos relacionados ao conceito de inteligência tem sido também abordados, há muito tempo, pela psicometria, também deixando margem para divergências teóricas. Nas teorias mais recentes (e.g., Teoria de Resposta ao Item, Lord, 1980) o conceito tem sido interpretado como um traço latente, cuja "natureza ontológica . . . deixa dúvidas se ele é concebido como um rótulo, representando uma síntese hipotética de um conjunto de comportamentos reais, ou como uma realidade mental" (Pasquali, 1996, p. 74).

Independentemente da interpretação sobre a natureza do fenômeno, as teorias psicométricas apresentam ainda concepções controversas com respeito à unidade do conceito. Pelo menos duas concepções diferentes podem ser encontradas na literatura: (a) inteligência interpretada como um fator geral (fator $g$ ), que permearia o nível de todas as realizações do indivíduo; e (b) inteligência como um conjunto de fatores específicos, que indicariam níveis diferentes de aptidões diversas (podendo incluir ou não as aptidões ligadas ao conhecimento) .

Apesar de vários autores frisarem a importância do fator geral, há divergências em relação à interpretação de sua natureza, como mencionado anteriormente. Por exemplo, alguns autores têm interpretado fator $g$ como um tipo de energia mental (e. g. Spearman, 1927), como uma simples regularidade estatística (e. g. . Thomson, 1939), como uma habilidade de raciocínio abstrato generalizada (e. g. Gustafsson, 1984), ou como um índice de medida de velocidade de processamento neural (Reed \& Jensen, 1992).

Outros teóricos (e.g., Thurstone, 1938; Guilford, 1959) não defenderam a existência de um único fator geral de inteligência, mas propuseram uma mente humana constituída por diferentes, e independentes, aptidões. Thurstone (1938) defendeu, por exemplo, que existem sete aptidões diferenciadas, a saber: compreensão verbal, fluência verbal, aptidão numérica, velocidade perceptiva, aptidão espacial, memória e raciocínio. Já Guilford (1959) defendeu um modelo com 150 aptidões, denominado Structure-of-Intellect . Recentemente, Gardner (1993/1995) propôs a existência de sete inteligências múltiplas: musical, corporal-cinestésica, lógicomatemática, lingüística, espacial, interpessoal e intrapessoal. Em trabalhos posteriores este mesmo autor adicionou a inteligência naturalística à lista original e sugeriu mais dois tipos de inteligência que seriam novas candidatas à lista: espiritual e existencial (cf.Sternberg \& Kaufman, 1998).

Adicionalmente às duas concepções de inteligência mencionadas acima (i.e., um fator geral ou vários fatores específicos), Howard (1993) identificou também um uso do termo como um adjetivo ao invés de um substantivo, de acordo com o qual inteligência seria uma característica de alguns comportamentos e não "uma coisa dentro da cabeça" (p. 32). Neste caso, seriam considerados inteligentes aqueles comportamentos do indivíduo bem adaptados às exigências do meio. $\mathrm{O}$ autor concluiu que o uso do mesmo termo para se referir a três conceitos de inteligência diferentes (i.e., fator geral, fatores específicos e adjetivo) não é problemático, desde que os autores especifiquem qual dos conceitos estão empregando.
Cabe ressaltar que as abordagens biológica, cognitiva e psicométrica não são necessariamente incompatíveis, pois podem vir a se complementar. Em anos recentes, esta tentativa tem acontecido principalmente entre a psicologia cognitiva e os enfoques biológicos, de um lado, e a psicologia cognitiva e a psicometria do outro.

Além dessas diferentes maneiras de teorizar sobre o conceito de inteligência, sua definição também parece ser influenciada por diferenças culturais, tendo em vista que as noções ocidentais sobre o fenômeno nem sempre são compartilhadas por outras culturas. Enquanto a cultura norte-americana enfatiza principalmente aspectos cognitivos da inteligência, algumas subculturas africanas, por exemplo, dão maior ênfase a habilidades sociais (cf. Sternberg \& Kaufman, 1998). Estas diferentes formas de interpretar o conceito em diferentes culturas e subculturas pode ter sido em parte responsável pelas intensas controvérsias em torno da utilização dos testes, cujos resultados fundamentaram discriminações raciais, étnicas, e sexuais, principalmente nos Estados Unidos (cf. Almeida, 1996; Greenfield, 1997; Halpern, 1997; Suzuki \& Valencia, 1997).

O conceito de inteligência também se mistura a outros conceitos na literatura psicológica, particularmente com raciocínio. Os dois conceitos têm sido concebidos como sinônimos em várias teorias psicológicas. Sternberg (1982) inicia um de seus trabalhos afirmando que esses dois conceitos são tão próximos que se torna difícil diferenciá-los. Posição semelhante foi apresentada por Spearman (1923) que definiu inteligência como a capacidade de raciocínio geral ou capacidade de apreender e estabelecer relações. Já para Almeida (1988), o raciocínio consiste na aptidão intelectual por excelência, que integra os processos cognitivos mais elaborados do ponto de vista intelectual, porém é apenas um dos componentes da inteligência. Esta última o autor define como todos os processos cognitivos, desde a recepção da informação à elaboração da resposta, passando pela codificação, memorização, aprendizagem, evocação e relacionamento da informação. Desse modo, o raciocínio se situaria preferencialmente nos componentes de tratamento de informação (cf. Almeida, 1988).

Este breve exame do uso do conceito de inteligência em psicologia serve para ilustrar algumas das muitas dificuldades conceituais na área. Não se encontra consenso sobre a natureza do fenômeno, sobre o tipo de abordagem a ser adotada (e.g., biológica, cognitiva e psicométrica), nem sobre o nível de análise adequado dentre cada uma dessas abordagens. Entretanto, alguns autores têm encarado a história do tópico com mais otimismo, ressaltando pontos consensuais que podem ser identificados na literatura. Um exemplo deste tipo de posição pode ser encontrado no trabalho de Ackerman e Heggestad (1997), no qual os autores, baseados principalmente em meta-análises de dados publicados, propõem um modelo hierárquico de inteligência que acomodaria grande parte dos achados na área. Este tipo de postura parece ser mais exceção do que regra na área, além de envolver pontos controversos, tais como o papel que técnicas de análise 
fatorial devem desempenhar em teorias sobre diferenças individuais (cf. Block, 1995). De qualquer forma, do ponto de vista conceitual, não se encontra muito acordo sobre as diferentes concepções de inteligência (para uma proposta de definição abrangente, entretanto, cf. Sternberg, 1997).

\section{Usos de "Inteligência" na Linguagem Cotidiana}

A análise do uso de conceitos psicológicos na linguagem cotidiana pode ser útil para esclarecer confusões conceituais em psicologia, na medida em que, como afirmou Wittgenstein (1953), é lá que eles encontram o seu "lar original". Quando um conceito é "importado" da linguagem cotidiana para qualquer linguagem científica, ele traz consigo uma carga de conotações, muitas das quais passam despercebidas no uso supostamente técnico. Uma análise da lógica do uso original do conceito pode vir a elucidar possíveis dificuldades decorrentes de conotações indesejáveis e/ou incompatíveis com os novos usos "científicos" (cf. Harzem, 1986; Harzem \& Miles, 1978; Oliveira-Castro, 1992, 1993, 2000; Oliveira-Castro \& Harzem, 1990; Peters, 1958; Ryle, 1949, 1953).

Ryle (1949) realizou uma das primeiras e mais abrangentes análises da lógica do uso de conceitos psicológicos na linguagem cotidiana. Naquele trabalho, o autor analisou a lógica do uso do conceito de inteligência, e outros associados a ele, ressaltando a distinção entre "saber como" (e.g., jogar bem xadrez) e "saber que" (e.g., conhecer as regras de xadrez). Naquela análise, Ryle associou o conceito de inteligência (versus estupidez) a "saber como" e conhecimento (versus ignorância) a "saber que". Descrevemos como inteligente aquelas ações desempenhadas com sucesso e que representam exercício de alguma habilidade da pessoa, no sentido de saber como realizar algo muito bem.

Um dos principais objetivos de Ryle (1949) era demonstrar os erros provenientes da doutrina intelectualista da mente, comum em teorias epistemológicas e psicológicas, a qual defende que para realizar qualquer ação inteligente, as pessoas devem seguir as regras que especificam como a ação deve ser realizada, ou seja, o "saber como" é sempre precedido pelo "saber que". Ryle refuta a mesma, demonstrando, em seu principal argumento, que a doutrina produz uma regressão ao infinito, já que o ato de escolher a regra adequada para qualquer ação pode ele mesmo ser caracterizado como mais ou menos inteligente, isto é, aplicar regras corretamente também é uma habilidade adquirida com a prática. Isto, por sua vez, implicaria em um ato anterior de escolher regras que possibilitem escolher a regra antes de agir, e assim por diante, indefinidamente. Além disso, o autor ressaltou que a prática bem sucedida geralmente precede a teoria sobre a prática, ou seja, o exercício de uma habilidade precede teorias sobre esta mesma habilidade. Antes de Aristóteles extrair as regras de inferência da lógica formal, as pessoas já argumentavam logicamente. Aliás, o fato das pessoas conseguirem tal feito foi o que permitiu a extração das regras.

Para Ryle (1949), portanto, uma ação é descrita como inteligente na linguagem cotidiana quando ela é o exercício bem sucedido de uma habilidade ou capacidade da pessoa.
O autor ressalta, ainda, que o uso típico do conceito envolve um desempenho bem sucedido em situações com algum tipo de novidade, pois a mera repetição de ações já estabelecidas dificilmente seriam descritas como inteligentes. $\mathrm{O}$ autor deixa claro que os casos de sucesso devido à sorte ou casuísmos não merecem essa caracterização, uma vez que a pessoa deve estar "atenta" ao que está fazendo, "tomando cuidado", seguindo critérios de bom desempenho. Em outras palavras, a pessoa deve estar pensando no que está fazendo. Em trabalhos posteriores, Ryle (1979), analisando o conceito de pensamento, constatou que o verbo pensar tem características do que ele denominou verbos adverbiais. Com essa expressão, o autor ressaltava que alguns verbos não indicam a ação que o indivíduo está desempenhando, mas caracterizam a forma de acordo com a qual uma ação está sendo desempenhada. Por exemplo, ao se descrever os soldados como obedecendo ou os alunos como atentando, não se sabe ao certo o que os soldados ou alunos estão fazendo. Eles poderiam estar fazendo quase qualquer coisa obedientemente ou atentamente. Verbos adverbiais, de acordo com Ryle (1979), não descrevem nenhuma ação específica e necessitam, logicamente, de verbos de ação, os quais eles caracterizam.

$\mathrm{O}$ uso do conceito de inteligência na linguagem cotidiana parece seguir a mesma lógica, no sentido de ter a função adverbial de caracterizar a maneira como as ações são executadas. Uma ação inteligente poderia ser quase qualquer ação que: (a) fosse bem sucedida, seguindo critérios específicos da tarefa; (b) representasse o exercício de uma determinada habilidade do indivíduo, isto é, o sucesso não foi fortuito, podendo ser repetido em situações futuras; e (c) ocorresse em uma situação envolvendo algum tipo de novidade, isto é, a ação não consistiu em simples repetição de uma ação já desempenhada, o que, por exemplo, distinguiria uma habilidade de um hábito. Por isso, ações muito diversas, tais como jogar xadrez, resolver equações matemáticas, comprar uma casa, proferir um discurso, organizar uma festa, realocar a mobília da sala, podem todas elas ser executadas mais ou menos inteligentemente, seguindo os critérios de sucesso específicos a cada uma das tarefas.

Sendo um conceito originalmente empregado na linguagem cotidiana, todos os aspectos adverbializados por inteligente são necessariamente vagos e dependentes do contexto específico (Harzem \& Miles, 1978; Ryle, 1954/1993, cap. 6). Portanto, as distinções entre sucesso versus fracasso, habilidade versus hábito, e situação nova versus situação conhecida, não possuem limites claros ou bem definidos. Esta falta de precisão do conceito não necessariamente reduz a sua utilidade na linguagem cotidiana, pois tampouco existem limites claros e bem definidos para distinguir "cadeira" de "poltrona", "vale" de "planície", "triste" de "alegre", "honesto" de "desonesto". Nem por isso tais conceitos deixam de ser utilizados na linguagem cotidiana, pois o nível adequado de precisão conceitual depende necessariamente do contexto no qual um conceito é empregado. Contrariamente ao que se observa na linguagem cotidiana, a utilidade de um conceito em uma linguagem técnico-científica é, muitas vezes, diretamente proporcional à sua precisão. 


\section{J. M. Oliveira-Castro e K. M. Oliveira-Castro}

Na linguagem cotidiana, no entanto, inteligente não é usado apenas para caracterizar ações específicas, mas também para caracterizar indivíduos. João pode ser descrito como mais inteligente que José. E nesse tipo de uso, estaria o conceito funcionando também como um advérbio? A lógica desse emprego na linguagem cotidiana parece ser a seguinte. João faz uma série de coisas com sucesso. Ele apresenta excelente desempenho nas disciplinas que cursa na escola, tanto em matemática como em português, como em artes. Além disso, João é muito hábil no seu relacionamento com colegas e professores, sendo também muito eficiente quando auxilia seus pais nas compras de supermercado. Em todas essas situações, João não se vê muito apertado quando obstáculos surgem pelo caminho; ele rápida e eficientemente encontra soluções alternativas. Portanto, a descrição de João como inteligente funciona como um resumo impreciso da maneira como ele executa uma diversidade de tarefas, isto é, a expressão funciona como um "resumo adverbial". Na descrição de João como inteligente, nada se afirma sobre as habilidades específicas nas quais ele se sobressai. A tentativa de especificar as habilidades costuma aparecer apenas quando há questionamentos sobre a descrição apresentada. Com base em que alguém afirma que João é mais inteligente que José? Este tipo de pergunta tende a gerar uma especificação das instâncias observadas ou conhecidas de sucesso de João comparadas com as de José.

A lógica do conceito não parece diferir muito da descrição de João como obediente ou apressado. A descrição como obediente afirma apenas que ele costuma seguir as instruções e ordens que recebe. João pode fazer quase qualquer coisa obedientemente ou não. Nada se afirma sobre as coisas que ele de fato faz, apenas que as faz, sejam quais forem, obedientemente. Novamente, se alguém questiona esta descrição, exemplos específicos de ações realizadas obedientemente serão provavelmente apresentados.

Este tipo de "resumo adverbial" pode ser de vários níveis diferentes. Entre os extremos da descrição do indivíduo (e.g., João é inteligente) e de ações específicas do mesmo (e.g., João realocou a mobília da sala inteligentemente), encontram-se outros níveis intermediários de descrição. Um dos níveis de análise muito freqüentemente empregado na linguagem cotidiana parece ser a caracterização de habilidades específicas dos indivíduos. João pode ser descrito como alguém que sabe inglês, matemática, joga tênis e é muito habilidoso com as palavras. Este tipo de descrição oferece um resumo de ações desempenhadas por João, em alguns contextos específicos, mas não descreve uma ação específica nem resume o conjunto de todas as habilidades de João. Os conceitos que descrevem habilidades seguem a lógica de conceitos disposicionais, do tipo "se tais e tais condições, então tais e tais ocorrências", extensamente discutidos por Ryle (1949). Quando se descreve um animal como ruminante, não se está descrevendo nenhuma ação específica que o animal esteja executando neste momento. Não se trata, portanto, de um conceito que relate uma ocorrência. A descrição de ruminante estabelece relações condicionais entre certas situações e certas ocorrências, no caso afirma que se o animal ingerir alimento, então ruminará (passado certo tempo, etc.). Lógica semelhante pode ser encontrada no uso de conceitos como solúvel, fumante, elástico. Descrever objetos ou pessoas com essas expressões não indica o relato de nenhuma ocorrência específica, mas descreve relações condicionais entre certos eventos (e.g., se colocado em água, então dissolve).

Apesar de conceitos disposicionais não relatarem ocorrências, a adequação do uso dos mesmos está vinculada a fatos ocorridos. A descrição de um animal como ruminante, para ser adequada, deve estar baseada em informações sobre ou observações de ocorrências de ruminação. Tais conceitos resumem uma série destas observações e fazem predição sobre o que acontecerá com este animal em certas situações.

Grande parte dos conceitos psicológicos encontrados na linguagem cotidiana também seguem esta mesma lógica disposicional. Quando descrevemos alguém como vaidoso, não estamos relatando nada sobre o que a pessoa está fazendo neste momento. Estamos, na verdade, afirmando que a pessoa tende, em certas situações, a agir e reagir de certas maneiras. De uma pessoa vaidosa, espera-se, por exemplo, que reaja com muita alegria, mesmo de disfarçada, ao receber elogios sobre sua aparência ou realizações, e que reaja com indignação e tristeza ao ouvir críticas a si ou elogios excessivos a outros. Além disso, esperar-se-ia que tal pessoa aproveite qualquer oportunidade para valorizar as coisas que faz, como falar sobre as mesmas freqüentemente, procurar o convívio de pessoas importantes, e assim por diante (Ryle, 1949). Vaidoso, portanto, é uma expressão baseada em informações ou observações que prediz certas ocorrências futuras. Muitas das expressões psicológicas seguem esta mesma lógica, tais como triste, raivoso, mau-caráter, mesquinho, hábil com as palavras e eficiente em matemática.

Uma importante diferença, também ressaltada por Ryle (1949) entre conceitos disposicionais como ruminante, fumante, solúvel, e grande maioria dos conceitos psicológicos é o nível de determinação das ocorrências que preenchem a cláusula "se ..., então ...". Nos casos como ruminante, apenas um tipo de ocorrência preenche a cláusula, ou seja, o conceito resume e prediz apenas que o animal ruminou e ruminará (e.g., fumar e dissolver). Os conceitos psicológicos, como vaidoso, por sua vez, incluem uma lista indeterminada de possíveis ocorrências que satisfazem a cláusula "se ..., então ...". Apesar de conseguirmos enumerar uma série de ações e reações que associaríamos com vaidade, nenhuma dessas seria, por si só, condição necessária ou suficiente para concluirmos que alguém é vaidoso. Tampouco seria qualquer dessas listas finita, pois novas situações e reações podem sempre ser incluídas na mesma. Ao caracterizar alguém como vaidoso, estamos geralmente nos baseando em vários itens de uma lista não muito bem definida, os quais não precisam ser os mesmos nas diferentes ocasiões nas quais usamos o conceito. Os diferentes empregos da expressão se assemelham aos membros de uma mesma família; apesar de todos se assemelharem, não há necessariamente nenhuma característica específica compartilhada por 
todos. Uns possuem um nariz parecido, outros, o andar, outros, a forma de falar (cf. Wittgenstein, 1953). Esta diferença entre ruminante e vaidoso foi caracterizada por Ryle (1949) com base na distinção entre conceitos disposicionais determinados ou fechados e determináveis ou abertos.

Portanto, a presente análise indica que a expressão inteligente é usada na linguagem cotidiana exercendo uma função adverbial, a qual indica que uma determinada ação é desempenhada eficientemente, com sucesso, mas não indica a ação específica que é desempenhada. Além disso, o emprego da expressão pode se dar em pelo menos três níveis diferentes, caracterizando, a saber, uma ação específica, habilidades de uma pessoa ou uma pessoa de forma geral. A descrição da habilidade é um resumo de ações específicas. A descrição da pessoa é um resumo de habilidades específicas.

Considerando que o conceito de raciocínio tem sido frequientemente associado ao de inteligência na literatura psicológica, uma análise do seu uso na linguagem cotidiana também se justifica. A expressão raciocínio também parece ter uma função adverbial. Quando se descreve uma pessoa como raciocinando, não se afirma nada sobre o que ela está a fazer especificamente. Esta pessoa pode estar resolvendo problemas matemáticos, ou procurando as chaves do seu carro, ou tentando realocar a mobília da sala. A expressão raciocinando, nesses casos, estaria indicando a maneira de acordo com a qual a pessoa estaria resolvendo problemas, procurando suas chaves ou realocando a mobília. O conceito parece indicar que a pessoa está seguindo passos mais ou menos sistemáticos na realização das tarefas. Resolver problemas matemáticos raciocinando sugere uma divisão do problema em etapas, a resolução das quais levaria à solução final do problema. Procurar as chaves raciocinando indica uma reconstituição sistemática dos lugares onde a pessoa esteve, procurando lembrar sistematicamente se ainda estava de posse das chaves. $\mathrm{O}$ advérbio raciocinando pode ser contrastado com outras maneiras de realizar as ações. Alguém pode tentar resolver problemas matemáticos adivinhando a resposta correta ou perguntando a alguém, como alguém pode tentar encontrar as chaves percorrendo de forma desorganizada alguns possíveis lugares. Novamente, podese fazer quase qualquer coisa raciocinando ou não.

Apesar de ambos os conceitos (i.e., inteligência e raciocínio) exercerem função adverbial na linguagem cotidiana, apresentando inclusive alguma sobreposição de uso, os conceitos não funcionam como equivalentes. Raciocinar, ou fazer algo raciocinando, consiste em realizar algo seguindo passos sucessivos, concatenados, mesmo que o resultado seja errado ou equivocado. Nesse sentido, tentar resolver um problema aritmético raciocinando pode não resultar em sucesso, isto é, apesar de terem sido seguidos passos sistemáticos, algum erro pode ter sido cometido no processo. Em casos como esse, poder-se-ia afirmar que o raciocínio não foi inteligente.

Por outro lado, nem todas as coisas que o indivíduo realiza inteligentemente envolvem raciocínio. Pode ser mencionado o exemplo de um brilhante pianista, que, apesar de tocar piano de forma fenomenal, não segue passos ou deduz logicamente premissas antes de apertar as teclas. Exemplos semelhantes podem ser encontrados no bom desempenho de um comediante, de um ator, de uma pessoa recitando a tabuada ou, até mesmo, de um político que profere um brilhante e decisivo discurso de improviso, movido pela emoção. Cabe ressaltar que a identificação das instâncias nas quais as pessoas executam atividades inteligentemente, seguindo passos sistemáticos, representa uma questão empírica, dependente de observações.

Portanto, nem toda ação caracterizada como inteligente envolve raciocínio, e nem toda ação que envolve raciocínio pode ser caracterizada como inteligente. Com base nessa análise, pode-se concluir que os conceitos raciocínio e inteligência têm usos diferentes na linguagem cotidiana.

\section{Usos na Linguagem Cotidiana Versus Usos em Psicologia}

Como mencionado anteriormente, não há consenso em Psicologia a respeito da natureza, definição ou nível de análise a serem adotados nas investigações sobre inteligência. $\mathrm{O}$ uso original deste conceito advém da linguagem cotidiana, onde o mesmo exerce funções adverbiais. Esta função adverbial pode explicar pelo menos parte essas divergências.

No que se refere à natureza do conceito, observa-se que o mesmo é por vezes interpretado como o nome de alguma característica biológica que está presente em maior grau nas pessoas descritas como muito inteligentes. Outras vezes, o conceito tem sido interpretado como o nome de uma habilidade mental geral. Em ambos esses casos, os autores parecem adotar uma teoria denotacionista (de referência) de significado, isto é, uma teoria que defende que o significado de uma expressão é o objeto (referente) por ela designado. De acordo com este tipo de teoria, a principal e talvez única função dos conceitos é nomear objetos, de tal forma que todos aqueles objetos que recebem o mesmo nome têm necessariamente algo em comum (para um contraste entre uma teoria denotacionista e uma teoria de uso ver Ryle, 1957/ 1975; Wittgenstein, 1953). Isto explicaria a prática encontrada na literatura que tratam o conceito de inteligência como o nome de uma característica das pessoas (biológica ou mental) apesar do mesmo ter função adverbial. Esta prática seria análoga a imaginar que obediência e pressa também se referem a características das pessoas. Como discutido anteriormente, no seu lar original, o uso de inteligente para se referir a pessoas funciona como um resumo adverbial vago e amplo da forma como determinado indivíduo realiza muitas e variadas ações.

Nada impede, no entanto, que o teórico considere a hipótese de encontrar algo em comum na constituição e/ou funcionamento do sistema nervoso das pessoas descritas como muito inteligentes, ausente ou menos predominante nas pessoas descritas como pouco inteligentes. Cabe ressaltar, porém, que neste caso trata-se de uma questão empírica a ser investigada, e não uma questão conceitual relacionada à definição de inteligência. Desta forma, a interpretação de 


\section{J. M. Oliveira-Castro e K. M. Oliveira-Castro}

inteligência como um construto ou conceito teórico seria mais congruente com o uso do mesmo na linguagem cotidiana, pois o mesmo poderia ser interpretado como um conceito que tem a principal função de descrever vaga e resumidamente a maneira como certos indivíduos agem.

As dificuldades encontradas para definir inteligência também podem, em parte, ser decorrência das funções adverbiais do conceito, na medida em que as ações descritas como inteligentes compartilham apenas o fato de serem bem-sucedidas. Definições abrangentes do conceito parecem se restringir a isto. Por exemplo, Sternberg (1997) definiu inteligência como "as habilidades mentais necessárias para adaptação ao, assim como a modelagem e seleção de, qualquer contexto ambiental". Esta proposta se parece com o uso na linguagem cotidiana, na medida em que basicamente afirma que a ação deve ser bem-sucedida e exercício de uma habilidade do indivíduo (apesar de sua interpretação do conceito de habilidade ser diferente do uso cotidiano do mesmo). No entanto, a definição é tão vaga que talvez seja de pouca utilidade científica.

Uma das discussões relacionadas ao emprego de inteligência, encontradas na literatura acadêmica, diz respeito à possibilidade ou não de descrever animais e objetos, como por exemplo computadores, como inteligentes (Searle, 1992; Turing, 1950). De acordo com a definição de Sternberg (1997), e o uso cotidiano da expressão, essas seriam extensões do uso típico, paradigmático, do conceito. Se tratando, no entanto, de um advérbio, a extensão não parece ser surpreendente, pois ao se descrever um programa de computador como inteligente, estaríamos afirmando, provavelmente, que o mesmo resolve com sucesso problemas novos. Estaríamos deixando de lado a idéia de que isto seja o exercício de uma habilidade da máquina. Os computadores pensam? A melhor resposta talvez seja: "sim e não". Como disse Wittgenstein (1953), diga o que você quiser, conquanto que isto não te impeça de ver as coisas como elas são.

$\mathrm{O}$ uso do conceito de inteligência em diferentes níveis, encontrado na linguagem cotidiana, para se referir a pessoas, habilidades ou ações específicas parece ter influenciado autores em psicologia. Como ressaltado por Howard (1993), diferentes autores têm conceitualizado inteligência como um fator geral, uma propriedade do comportamento ou um conjunto de aptidões, desenvolvendo abordagens divergentes entre si. A presente análise sugere que estes são níveis diferentes do mesmo uso adverbial do conceito, os quais não seriam necessariamente incompatíveis. Característica semelhante pode ser encontrada em outros conceitos adverbiais, tal como obediente. Um ato específico pode ser descrito como obediente, bem como uma pessoa de forma geral. Além disso, o resumo adverbial obediente pode também ser aplicado a certos contextos específicos de interesse, que pertenceriam a um nível intermediário de análise. Uma criança, por exemplo, pode ser descrita como muito obediente na escola, mas não em casa. Isto seria análogo a afirmar que João se sobressai muito em matemática, mas é fraco em português. Essa possibilidade de aplicar uma expressão adverbial a diferentes níveis descritivos pode explicar, em parte, a falta de concordância entre os autores com respeito ao número e níveis de fatores relacionados ao conceito. Em quase qualquer contexto, as ações podem ser adverbializadas como bemsucedidas ou não, o que talvez ajude a compreender a tendência de multiplicação de níveis e tipos de inteligências.

Um outro ponto muito discutido nas investigações sobre inteligência diz respeito a abrangência e adequação das definições para diferentes culturas e sub-culturas. Os resultados da aplicação de testes a pessoas de diferentes sub-grupos raciais, sexuais, étnicos e culturais têm gerado algumas das mais fervorosas controvérsias na história da psicologia (cf. Almeida, 1996; Greenfield, 1997; Halpern, 1997; Suzuki \& Valencia, 1997). Parte desse problema pode estar baseado na característica adverbial do conceito, na medida em que o mesmo tem como principal função caracterizar qualquer ação como bem sucedida. Como diferentes culturas e sub-culturas valorizam, considerando como indicador de sucesso, diferentes ações e/ou diferentes critérios de sucesso para uma mesma ação, elas adotam diferentes conceitos de inteligência (cf. Sternberg e Kaufman, 1998). Não é de se estranhar, portanto, que a aplicação de um conceito desenvolvido no contexto da cultura ocidental industrializada gere controvérsias e problemas ao ser aplicado a culturas diferentes.

A relação entre os conceitos de inteligência e raciocínio por vezes encontrada na literatura em psicologia não está de acordo com o uso dos mesmos na linguagem cotidiana. Como mencionado anteriormente, os dois conceitos têm sido interpretados como equivalentes por alguns autores (Spearman,1923; Sternberg ,1982). De acordo com esse ponto de vista, portanto, todo raciocínio seria inteligente e todo ato inteligente seria realizado "raciocinando". Na linguagem cotidiana, um raciocínio pode não ser inteligente e nem todo ato inteligente é realizado raciocinando. Essa proposta eliminaria importantes distinções existentes na linguagem cotidiana. Se tornaria impossível distinguir raciocínios corretos de incorretos, isto é, não saberíamos diferenciar argumentos legítimos de falaciosos, e um erro de João resolvendo um problema de matemática implicaria que ele não estava raciocinando. Além disso, seriam indistinguíveis atos bemsucedidos que seguiram passos sistemáticos daqueles que não o fizeram, impossibilitando a caracterização de uma performance no piano ou o desempenho em uma partida de tênis como inteligentes.

Já a interpretação de raciocínio como um componente da inteligência (cf. Almeida, 1988) não parece gerar contradições, na medida em que uma das forma de fazer algo inteligentemente é raciocinando (como pode ser também usando a intuição, ou a sensibilidade) . Nesse caso, trata-se de um advérbio (raciocinando) com a função de modificar outro advérbio (inteligentemente).

\section{Conclusão}

A presente análise indicou que o conceito de inteligência exerce uma função adverbial na linguagem cotidiana, a qual indica que uma ação foi bem-sucedida, em uma situação nova, sendo o exercício de uma habilidade do indiví- 
duo. Esta função adverbial do conceito pode auxiliar na compreensão de algumas das divergências encontradas na literatura em psicologia, onde não há consenso sobre a natureza, definição e nível de análise adequados nas investigações sobre inteligência. Divergências e diferenças com relação ao conceito em diferentes culturas também parece estar relacionados ao aspecto adverbial de inteligência, na medida em que cada cultura defende critérios diferentes para o que seja uma ação bem-sucedida. A análise realizada ilustra as dificuldades que podem advir da "importação" de conceitos da linguagem cotidiana para a linguagem teórico-empírica em psicologia, pois, por mais que os teóricos procurem defini-los "operacionalmente", o conceito não perde as funções que exerce no seu lar original. A adoção de termos técnicos, criados especificamente para descrever e explicar os fenômenos investigados, pode vir a reduzir esse tipo de problema.

\section{Referências}

Almeida, L.S. (1988). O Raciocínio Diferencial dos Jovens: Avaliação, Desenvolvimento e Diferenciação. Porto: Instituto Nacional de Investigação Científica.

Almeida, L.S. (1994). Inteligência: Definição e Medida. Aveiro, Portugal: CIDINE.

Almeida, L.S. (1996). Considerações em torno da medida da inteligência. Em L. Pasquali (Org.), Teoria e Métodos de Medida em Ciências do Comportamento (pp. 199-223). Brasília: INEP, 199-223.

Ackerman, P.L., \& Heggestad, E.D. (1997). Intelligence, personality and interests: Evidence for overlapping traits. Psychological Bulletin, 121, 219-245.

Block, J. (1995). A contrarian view of the five-factor approach to personality description. Psychological Bulletin, 117, 187-215.

Galton, F. (1869). Hereditary Genius. London: MacMillan.

Galton, F. (1883). Inquiry into Human Faculty and Its Development. London: Macmillan.

Gardner, H. (1995). Inteligências Múltiplas: A Teoria e a Prática (M.A.V. Veronese, Trad.). Porto Alegre: Artes Médicas. (Trabalho publicado originalmente em 1993).

Greenfield, P.M. (1997). You can't take with you: Why ability assessments don't cross cultures. American Psychologist, $52,1115-1124$

Guilford, J.P. (1959). Three faces of intellect. American Psychologist, 14, 469-479.

Gustafsson, J.E. (1984). A unifying model for the structure of intellectualabilities. Intelligence, 8, 179-203.

Haier, R.J., Nuechterlein, K.H., Hazlett, E., Wu, J.C., \& Paek, J. (1988). Cortical glucose metabolic rate correlates of abstract reasoning and attention studied with positron tomography. Intelligence, 12, 199-217.

Halpern, D.F. (1997). Sex differences in intelligence: Implications for education. American Psychologist, 52, 1091-1102.

Harzem, P. (1986). The language trap and the study of pattern in human action. Em T. Thompson \& M.D. Zeiler (Orgs.) Analysis and Integration of Behavioral Units (pp. 45-53). Hillsdale, NJ: Erlbaum.
Harzem, P., \& Miles, T.R. (1978). Conceptual Issues in Operant Psychology. New York: John Wiley \& Sons.

Howard, R.W. (1993). On what intelligence is. British Journal of Psychology, 84, 27-37.

Lord, F.M. (1980). Applications of Item Response Theory to Practical Testing Problems. Hillsdale, NJ: Erlbaum.

Newell, A., \& Simon, H.A. (1972). Human Problem Solving. Englewood Cliffs, NJ: Prentice-Hall.

Oliveira-Castro, J.M. (1992). "Fazer na cabeça": Uso metafórico e negativo. Psicologia: Teoria e Pesquisa, 8, 267-272.

Oliveira-Castro, J.M. (1993). "Fazer na cabeça": Análise conceitual, demonstrações empíricas e considerações teóricas. Psicologia USP, 4, 171-202.

Oliveira-Castro, J.M. (2000). The negative function of "doing in the head" and behavioristic interpretations of private events. The Mexican Journal of Behavior Analysis, 26, 1-25.

Oliveira-Castro, J.M., \& Harzem, P. (1990). Level of aspiration and the concept of goal. The Mexican Journal of Behavior Analysis, 16, 41-53.

Pasquali, L. (1996). Medida psicométrica. Em L. Pasquali (Org.) Teoria e Método de Medida em Ciências do Comportamento (pp. 73-115). Brasília: INEP.

Peters, R.S. (1958). The Concept of Motivation. London: Routledge \& Kegan Paul.

Piaget, J. (1952). The Origins of Intelligence in Children. New York: International Universities Press.

Reed, T.E. \& Jensen, A.R. (1992). Conduction velocity in a brain nerve pathway of norma adults correlates with intelligence level. Intelligence, 16, 259-272.

Ryle, G. (1949). The Concept of Mind. London: Hutchinson \& Co.

Ryle, G. (1953). Ordinary language. The Philosophical Review, $62,167-186$.

Ryle, G. (1975). A teoria da significação. Em Os pensadores, v. 52 (pp. 59-76). São Paulo: Abril. (Trabalho publicado originalmente em 1957).

Ryle, G. (1979). On Thinking. Totowa, NJ: Rowman \& LIttlefield.

Ryle, G. (1993). Dilemas. (A. Cabral, Trad.) São Paulo: Martins Fontes. (Trabalho publicado originalmente em 1954).

Searle, J. (1992). The Rediscovery of the Mind. Cambridge, MA: MIT Press.

Spearman, C. (1923). The Nature of Intelligence and the Principles of Cognition. London: Macmillan.

Spearman, C. (1927). The Abilities of Man: Their Nature and Measurement. New York: Macmillan.

Sternberg, R.J. (1977) Intelligence, Information Processing, and Analogical Reasoning: The Componential Analysis of Human Abilities. Hillsdale, NJ: Erlbaum.

Sternberg, R. J. (1982). Reasoning, problem-solving, and intelligence. In R.J. Sternberg (Ed.) Handbook of Human Intelligence. Cambridge, M.A.: Cambridge Univ. Press.

Sternberg, R.J. (1997). The concept of intelligence and its role in lifelong learning and success. American Psychologist, 52, 10301037.

Sternberg, R.J., \& Kaufman, J.C. (1998). Human abilities. Annual Review of Psychology, 49, 479-502. 
Suzuki, L.A., \& Valencia, R.R. (1997). Race-ethnicity and measured intelligence: Educational implications. American Psychologist, 52, 1103-1114.

Thomson, G.H. (1939). The Factorial Analysis of Human Abilities. Boston: Houghton Mifflin.

Thurstone, L.L. (1938). Primary Mental Abilities. Chicago: University Chigago Press.
Turing, A.M. (1950). Computing machinery and intelligence. Mind, $59,433-460$.

Willerman, L., Schultz, R., Rutledge, J.M., \& Bigler, E. D. (1991). In vivo brain size and intelligence. Intelligence, 15, 223-228.

Wittgenstein, L. (1953). Philosophical Investigations. New York: Macmillan. 